\title{
Achievements of the First 4 Years of the International Geodynamics and Earth Tide Service (IGETS) 2015-2019
}

\author{
Jean-Paul Boy, Jean-Pierre Barriot, Christoph Förste, Christian Voigt, \\ and Hartmut Wziontek
}

\begin{abstract}
We present the activities and improvements of the International Geodynamics and Earth Tide Service (IGETS) over the last four years. IGETS collects, archives and distributes long time series from geodynamic sensor, in particular superconducting gravimeter data currently from more than 40 stations and 60 different sensors. In addition to the raw 1$\mathrm{s}$ and 1-min gravity and atmospheric pressure data (Level 1), IGETS produces end-user products on different levels. These include gravity and atmospheric pressure data corrected for major instrumental perturbations and ready for tidal analysis (Level 2). Since 2019, IGETS provides gravity residuals corrected for most geophysical contributions (Level 3) which can be used directly for geophysical applications without any expert knowledge in the processing of gravimetric time series.
\end{abstract}

Keywords

IAG and IGFS service · Superconducting gravimeters

\section{$1 \quad$ Introduction}

The International Geodynamics and Earth Tide Service (IGETS) was established at the 2015 IUGG meeting in Prague as an official service of the IAG within the IGFS. Its main objective is to provide a service to monitor temporal variations of the Earth gravity field through long-term records from ground gravimeters, including superconducting gravimeters (SG) and other geodynamic sensors, such as tiltmeters, extensometers, etc. (Voigt et al. 2016). IGETS continues the activities of the Global Geodynamic Project

J.-P. Boy $(\bowtie)$

IPGS (UMR 7516), Université de Strasbourg/EOST, CNRS,

Strasbourg Cedex, France

e-mail: jeanpaul.boy@unistra.fr

J.-P. Barriot

Observatoire Géodésique de Tahiti, University of French Polynesia

(UPF), Tahiti, French Polynesia

C. Förste $\cdot$ C. Voigt

GFZ German Research Centre for Geosciences, Potsdam, Germany

H. Wziontek

Federal Agency for Cartography and Geodesy (BKG), Leipzig,

Germany
(Crossley and Hinderer 2009) to provide support to geodetic and geophysical research activities using SG data within the context of an international network. IGETS also continues the activities of the International Center for Earth Tides, in particular, in collecting, archiving and distributing Earth tide records from long series of gravimeters, and other geodynamic sensors.

We present here the status and progress of IGETS and its different products after four years of existence for the support of geophysical research activities. We first document the observation network, with 42 existing stations equipped by 60 different instruments, including seven double-sphere SGs. We then describe the three levels of data products, from the raw 1-s or 1-min gravity and atmospheric pressure records (Level 1), to the pre-processed datasets ready for tidal analysis (Level 2) and the gravity residuals corrected for major geophysical contributions (Level 3).

\section{Observation Network}

In 2016, the IGETS data base was set up at GFZ with GGP data from 32 different stations and has increased its number of stations by $25-42 \%$ according to the sta- 

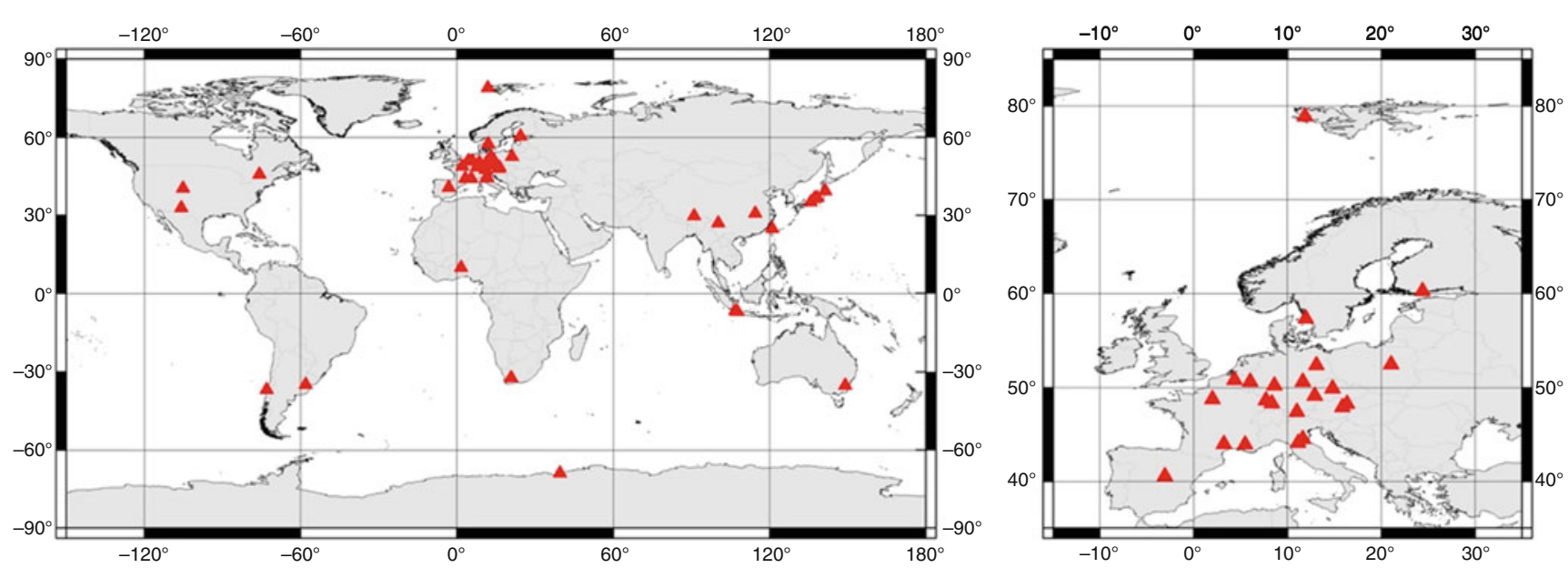

Fig. 1 Map of the 42 stations contributing to the IGETS data base

tus from summer 2019 (Fig. 1). IGETS is interested in collecting more long time series of geodynamic sensors. Benefits for station operators and data providers are the longterm storage of their data sets, the provision of different processing levels and an optional DOI assignment by the research repository of GFZ Data Services. This guarantees best practice with regard to open data policy. The visibility and usage of IGETS has also been increased with a steadily increasing number of almost 500 registered users of the data base.

\section{Data Products}

A detailed documentation of the IGETS data products and the data base is provided by Voigt et al. (2016). Three different products of the SG time series are stored in monthly files:

- Raw gravity and local atmospheric pressure records sampled at 1 or $2 \mathrm{~s}$, in addition to the same records decimated at 1-min samples (Level 1 products). These are uploaded by each station operator.

- Gravity and atmospheric pressure data at 1-min and 1$\mathrm{h}$ sampling corrected for instrumental perturbations, ready for tidal analysis. This product is derived from the previous datasets and is available in two versions computed by UPF and EOST (Level 2 products).

- Gravity residuals in $1 \mathrm{~min}$ sampling after particular geophysical corrections (including solid Earth tides, polar motion, tidal and non-tidal loading effects). This product is derived from the previous dataset of EOST and is also computed by EOST (Level 3 products).

\subsection{Level 1}

Available raw gravity and atmospheric pressure data from the station operators are shown in Table 1 for the different IGETS stations and sensors. As raw gravity data are not calibrated, each station operator is asked to provide amplitude and phase calibrations and their changes over time if existing in a separate calibration file. Otherwise this information is still provided in the Level 1 header files. In addition, $\log$ files are provided by the station operators documenting periods of instrumental disturbances inducing steps, gaps and large spikes with regard to a subsequent processing.

\subsection{Level 2}

Level 2 data products are currently computed by two different analysis centers: primary at UPF (University of French Polynesia, Tahiti) and secondary also at EOST (Ecole et Observatoire des Sciences de la Terre, Strasbourg, France). This pre-processing aims to remove instrumental perturbations from the Level 1 raw gravity and atmospheric pressure data, producing time series ready for tidal analysis. Level 2 products by UPF are available for all stations and sensors providing Level 1 data and are updated on a regular basis. Level 2 products by EOST were initially computed for 26 stations and 36 sensors with long time series.

While the UPF processing follows the well-known approaches of GGP and ICET, the EOST processing was introduced in 2019 and is described in the following. Raw 1-min gravity and atmospheric pressure (Level 1 data) are first calibrated using the available calibration files. First, interpolated hourly surface pressure from MERRA2 (Gelaro 
Table 1 Temporal coverage of Level 1 data provided to IGETS from station operators

\begin{tabular}{|c|c|c|c|c|c|c|c|c|c|c|c|c|c|c|c|c|c|c|c|}
\hline Station & Sensor & 1989 & \begin{tabular}{|l|l|l|}
90 & 91 & 92 \\
\end{tabular} & 93 & 949 & \begin{tabular}{l|l|}
95 & 96 \\
\end{tabular} & 9798 & 992 & 2000 & $01 \mid 02$ & \begin{tabular}{|l|l|l|l|}
03 & 04 \\
\end{tabular} & \begin{tabular}{|l|l|l|}
4 & 05 & 06 \\
\end{tabular} & \begin{tabular}{|l|l|l|}
07 & 08 \\
\end{tabular} & 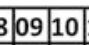 & \begin{tabular}{|l|l|}
11 & 12 \\
\end{tabular} & \begin{tabular}{|l|l|}
2 & 13 \\
\end{tabular} & \begin{tabular}{|l|l|}
14 & 15 \\
\end{tabular} & \begin{tabular}{|l|l|}
16 & 17 \\
\end{tabular} & \begin{tabular}{|l|l|}
18 & 19 \\
\end{tabular} \\
\hline Apache Point & ap046 & & & & & & & & & & & & & & & & & & \\
\hline Bad Homburg & bh030-1 & & & & & & & & & & & & & & & & & & \\
\hline Bad Homburg & bh030-2 & & & & & & & & & & & & & & & & & & \\
\hline Bad Homburg & bh044 & & & & & & & & & & & & & & & & & & \\
\hline Bandung & ba009 & & & & & & & & & & & & & & & & & & \\
\hline Borowa Gora & $\operatorname{bg} 027$ & & & & & & & & & & & & & & & & & & \\
\hline Borowa Gora & bg1036 & & & & & & & & & & & & & & & & & & \\
\hline Boulder & bo024 & & & & & & & & & & & & & & & & & & \\
\hline Brasimone & br015 & & & & & & & & & & & & & & & & & & \\
\hline Brussels & be003 & & & & & & & & & & & & & & & & & & \\
\hline Canberra & cb031 & & & & & & & & & & & & & & & & & & \\
\hline Cantley & $\mathrm{ca0} 12$ & & & & & & & & & & & & & & & & & & \\
\hline Cibinong & ci022 & & & & & & & & & & & & & & & & & & \\
\hline Concepcion & tc038 & & & & & & & & & & & & & & & & & & \\
\hline Conrad & $\operatorname{co0} 25$ & & & & & & & & & & & & & & & & & & \\
\hline Djougou & dj060 & & & & & & & & & & & & & & & & & & \\
\hline Esashi & es007 & & & & & & & & & & & & & & & & & & \\
\hline Hsinchu & hs048 & & & & & & & & & & & & & & & & & & \\
\hline Kamioka & ka016 & & & & & & & & & & & & & & & & & & \\
\hline Kyoto & ky009 & & & & & & & & & & & & & & & & & & \\
\hline Larzac & la002 & & & & & & & & & & & & & & & & & & \\
\hline La Plata & Ip038 & & & & & & & & & & & & & & & & & & \\
\hline Lhasa & Ih057 & & & & & & & & & & & & & & & & & & \\
\hline \begin{tabular}{|l} 
Lijiang \\
\end{tabular} & li066 & & & & & & & & & & & & & & & & & & \\
\hline Matsushiro & $\mathrm{ma011}$ & & & & & & & & & & & & & & & & & & \\
\hline Medicina & $\mathrm{mc023}$ & & & & & & & & & & & & & & & & & & \\
\hline Membach & $\mathrm{mb021}$ & & & & & & & & & & & & & & & & & & \\
\hline Metsahovi & me013 & & & & & & & & & & & & & & & & & & \\
\hline Metsahovi & $\mathrm{me} 020$ & & & & & & & & & & & & & & & & & & \\
\hline Metsahovi & me022 & & & & & & & & & & & & & & & & & & \\
\hline Metsahovi & me073-1 & & & & & & & & & & & & & & & & & & \\
\hline Metsahovi & me073-2 & & & & & & & & & & & & & & & & & & \\
\hline Mizusawa & mi007 & & & & & & & & & & & & & & & & & & \\
\hline Moxa & mo034-1 & & & & & & & & & & & & & & & & & & \\
\hline Moxa & mo034-2 & & & & & & & & & & & & & & & & & & \\
\hline Ny-Alesund & ny039 & & & & & & & & & & & & & & & & & & \\
\hline Onsala & os054 & & & & & & & & & & & & & & & & & & \\
\hline Pecny & pe050 & & & & & & & & & & & & & & & & & & \\
\hline Potsdam & po018 & & & & & & & & & & & & & & & & & & \\
\hline \begin{tabular}{|l|} 
Rustrel \\
\end{tabular} & ru024 & & & & & & & & & & & & & & & & & & \\
\hline Schiltach & bf056-1 & & & & & & & & & & & & & & & & & & \\
\hline Schiltach & bf056-2 & & & & & & & & & & & & & & & & & & \\
\hline Strasbourg & st023 & & & & & & & & & & & & & & & & & & \\
\hline Strasbourg & st026 & & & & & & & & & & & & & & & & & & \\
\hline Sutherland & su037-1 & & & & & & & & & & & & & & & & & & \\
\hline Sutherland & su037-2 & & & & & & & & & & & & & & & & & & \\
\hline Sutherland & su052 & & & & & & & & & & & & & & & & & & \\
\hline Syowa & sy016 & & & & & & & & & & & & & & & & & & \\
\hline Trappes & tr005 & & & & & & & & & & & & & & & & & & \\
\hline Vienna & vi025 & & & & & & & & & & & & & & & & & & \\
\hline Wettzell & we006 & & & & & & & & & & & & & & & & & & \\
\hline Wettzell & we 029-1 & & & & & & & & & & & & & & & & & & \\
\hline Wettzell & we029-2 & & & & & & & & & & & & & & & & & & \\
\hline Wettzell & we030-1 & & & & & & & & & & & & & & & & & & \\
\hline Wettzell & we030-2 & & & & & & & & & & & & & & & & & & \\
\hline Wettzell & we103 & & & & & & & & & & & & & & & & & & \\
\hline Wuhan & wu004 & & & & & & & & & & & & & & & & & & \\
\hline Wuhan & wu065 & & & & & & & & & & & & & & & & & & \\
\hline Yebes & ys064 & & & & & & & & & & & & & & & & & & \\
\hline Zugspitze & $2 u 052$ & & & & & & & & & & & & 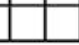 & 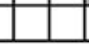 & - & - & & 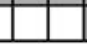 & \\
\hline
\end{tabular}


et al. 2017) reanalysis model is removed from the pressure data. Then these residuals are manually corrected for eventual offsets, and gaps are filled by linear interpolation. The de-gapped series is then corrected for the remaining perturbations (spikes) using a threshold on its derivative, following the procedure of Crossley et al. (1993). The full pressure is then restored by adding back the surface pressure from MERRA2.

For gravity data, the methodology is similar: The calibrated gravity values are corrected for a local tidal model as well as polar motion and local air pressure effects. Offsets are then manually corrected, gaps are filled by linear interpolation, and remaining perturbations (spikes, earthquakes) are corrected using a threshold on the derivative of the gravity residuals. The corrected gravity signal is then restored by adding back the modeled tidal signal, polar motion and air pressure effects. A major advance of this processing is that corrected offsets and filled gaps are documented in separate channels.

Differences between the Level 2 data sets have been detected at some stations, which are dominated by discrepancies in the step corrections, reaching up to $100 \mathrm{~nm} / \mathrm{s}^{2}$. Different strategies for spike reduction and gap filling causing differences of a few tens of $\mathrm{nm} / \mathrm{s}^{2}$ (Hinderer et al. 2002). Also differences in air pressure may reach up to several $\mathrm{hPa}$ in sections where gaps were filled. Currently, the processing strategies of UPF and EOST are evaluated, therefore no recommendation for a specific Level 2 data set is given. IGETS strives for standardization of the Level 2 products in the near future.

\subsection{Level 3}

Level 3 data are currently computed from the Level 2 data processed by EOST. Gravity residuals with 1-min resolution are computed after subtracting from the Level 2 data:

- Solid Earth tides and ocean tidal loading,

- Atmospheric loading,

- Polar motion and length-of-day induced gravity changes,

- Instrumental drift.

Tidal gravity variations are computed differently for the long-period tides and for the diurnal and sub-diurnal bands:

- At high frequency, a local tidal model, adjusted by leastsquares, is used.

- At low frequency, we model the tidal signal using the DDW99 gravimetric factor (Dehant et al. 1999) and HW95 tidal potential (Hartmann and Wenzel 1995) for the Solid Earth tides, and FES2014b (Carrère et al. 2016) for the ocean tidal loading using its seven different constituents ( $\mathrm{Sa}, \mathrm{Ssa}, \mathrm{Mm}, \mathrm{Msf}, \mathrm{Mf}, \mathrm{Mtm}$ and Msqm).
Atmospheric loading is computed according to Boy et al. (2002), using MERRA2 (Gelaro et al. 2017) hourly surface pressure, and assuming an inverted barometer ocean response to pressure. The MERRA2 pressure is replaced by the 1-min local pressure record for angular distance less than $0.10^{\circ}$ to the station. The polar motion and length-ofday induced gravity variations are modeled using the IERS EOPC04 daily series (Wahr 1985), and assuming a $\delta_{2}$ factor of 1.16. We also model ocean pole tide as a self-consistent equilibrium response (Agnew and Farrell 1978). Depending on the sensor, the instrumental drift is generally modeled as a polynomial or an exponential function (Van Camp and Francis 2007). When available, we use time series from absolute gravimeters for the adjustment.

The Level 3 gravity residuals can be used directly by scientists without any expert knowledge in the processing and reduction of gravimetric time series for specific applications e.g. in geodesy, geophysics or hydrology. In addition, the provision of the effect from various reduction models in separate channels easily allows restoring the signal of interest back to the gravity residuals.

\section{Scientific Applications of IGETS Data}

Since its establishment in 2015, IGETS data has been used as the basis for a large number of scientific studies in various disciplines that were only possible by the global integration of the individual stations. In the following we can only give a brief selection. Mikolaj et al. (2019) provide uncertainty estimates of SG reductions for various IGETS stations especially with regard to subsequent hydrological signal separation. Bogusz et al. (2018) do inter-comparisons of nearby GPS and SG time series at several IGETS stations for an improved understanding of the structure, dynamics and evolution of the system Earth. Ziegler et al. (2016) and Gruszczynska et al. (2017) have estimated the gravimetric pole tide from long SG time series. A recent study by Cui et al. (2018) analyzes the time variability of free core nutation (FCN) period based on several IGETS stations, while Sun et al. (2019) re-analyze the Earth's background free oscillations using various SG data sets. Xu et al. (2019) investigated the Earth toroidal modes after Sumatra-Andaman earthquakes using various SGs. Karkowska and Wilde-Piórko (2019) have used raw gravity data from IGETS stations to study long-period surface waves. Very recently, first attempts have been made to apply the IGETS network for detection of dark matter (Horowitz and Widmer-Schnidrig 2020; McNally and Zelevinsky 2020; Hu et al. 2019).

Full studies of the only equatorial station, Djougou in Niger (Africa), were performed by Hinderer et al. (2019, 2020). Antokoletz et al. (2019) conducted a preliminary study of the South American station of La Plata (Argentina) 


\section{$5 \quad$ Conclusions}

Since its establishment in 2015, IGETS has collected, archived and distributed superconducting gravimeter data from more than 40 stations and 60 different instruments. In addition to the raw 1-s and 1-min gravity and atmospheric pressure data (Level 1), IGETS is producing end-user products, including gravity and pressure data corrected for major instrumental perturbations (Level 2), ready for tidal analysis, and gravity residuals corrected for geophysical contributions (Level 3). The Level 2 data are produced by the two analysis centers located at the University of Polynesia and EOST, Strasbourg, France; the level 3 data are produced by EOST. The IGETS data base including all data sets is hosted by GFZ. The access for data users is free after a mandatory registration. Interested operators of geodynamic sensors are invited to join IGETS as data producers.

Acknowledgements We thank all station operators for providing their valuable data to IGETS.

\section{References}

Agnew DC, Farrell WE (1978) Self-consistent equilibrium ocean tides. Geophys J R Astr Soc 55:171-181

Antokoletz ED, Wziontek H, Tocho C (2019) First six months of superconducting gravimetry in Argentina. In: International symposium on gravity, geoid and height systems 2016, Thessaloniki, 19-23 September 2016, pp 111-118 https://doi.org/10.1007/1345_2017_13

Bogusz J, Rosat S, Klos A, Lenczuk A (2018) On the noise characteristics of time series recorded with nearby located GPS receivers and superconducting gravity meters. Acta Geod Geophys 53:201-220. https://doi.org/10.1007/s40328-018-0212-5

Boy J-P, Gegout P, Hinderer J (2002) Reduction of surface gravity data from global atmospheric pressure loading. Geophys J Int 149:534545

Carrère L, Lyard F, Cancet M, Guillot A, Picot N (2016) FES 2014, a new tidal model - validation results and perspectives for improvements. In: ESA living planet conference, Prague, 9-13 May 2016

Crossley D, Hinderer J (2009) A review of the GGP network and scientific challenges. J Geodyn 48:299-304

Crossley D, Hinderer J, Jensen O, Xu HH (1993) A slew rate detection criterion applied to SG data processing. Bull d'Inf Marées Terr 117:8675-8704

Cui X, Sun H, Xu J, Zhou J, Chen X (2018) Detection of free core nutation resonance variation in Earth tide from global superconducting gravimeter observations. Earth Planets Space 70:199. https://doi. org/10.1186/s40623-018-0971-9

Dehant V, Defraigne P, Wahr J (1999) Tides for a convective earth. J Geophys Res 104(B1):1035-1058. https://doi.org/10.1029/ 1998JB900051

Gelaro R, McCarty W, Suarez MJ et al (2017) The modern-era retrospective analysis for research and applications, version-2 (MERRA2). J Clim 30:5419-5454
Gruszczynska M, Rosat S, Klos A, Janusz Bogusz J (2017) Providing long-term trend and gravimetric factor at Chandler period from superconducting gravimeter records by using singular spectrum analysis along with its multivariate extension. In: AGU Fall Meeting, New Orleans, 11-15 December 2017, G11C-0423

Hartmann T, Wenzel HG (1995) The HW95 tidal potential catalogue. Geophys Res Lett 22(24):3553-3556. https://doi.org/10.1029/ 95GL03324

Hinderer J, Rosat S, Crossley D, Amalvict M, Boy J-P, Gégout P (2002) Influence of different processing methods on retrieval of gravity signal from GGP data. Bull Infor Marèes Terr 135:10653-10667

Hinderer J, Riccardi U, Rosat S, Boy J-P, Hector B, Calvo M, Littel F, Bernard J-D (2019) A study of the solid Earth tides, ocean and atmospheric loadings using an 8-year record (2010-2018) from superconducting gravimeter OSG-060 at Djougou (Benin, West Africa). J Geodyn 134:101692. https://doi.org/10.1016/j.jog.2019. 101692

Hinderer J, Hector B, Riccardi U, Rosat S, Boy J-P, Calvo M, Littel F, Bernard J-D (2020) A study of the monsoonal hydrology contribution using a 8 year record (2010-2018) from superconducting gravimeter OSG-060 at Djougou (Benin, West Africa). Geophys J Int 22(1):431-439. https://doi.org/10.1093/gji/ggaa027

Horowitz CJ, Widmer-Schnidrig R (2020) Gravimeter search for compact dark matter objects moving in the Earth. Phys Rev Lett 124(5), 051102. https://doi.org/10.1103/PhysRevLett.124.051102

Hu W, Lawson M, Budker D, Figueroa NL, Jackson Kimball DF, Mills Jr. AP, Voigt C (2019) A network of superconducting gravimeters as a detector of matter with feeble non-gravitational coupling. arXiv:1912.01900v1 (submitted to EPJD in 2020)

Karkowska K, Wilde-Piórko M (2019) How can gravimeters improve recordings of earthquakes? Geophysical Research Abstracts 21, EGU2019-427

McNally RL, Zelevinsky T (2020) Constraining domain wall dark matter with a network of superconducting gravimeters and LIGO. arXiv:1912.06703v1 (submitted to EJPD in 2020)

Mikolaj M, Reich M, Güntner A (2019) Resolving geophysical signals by terrestrial gravimetry: a time domain assessment of the correction-induced uncertainty. JGR: Solid Earth 124(2):2153-2165. https://doi.org/10.1029/2018JB016682

Sun H, Zhang M, Xu J, Chen X (2019) Reanalysis of background free oscillations using recent SG data. Terr Atmos Ocean Sci 30:757-763. https://doi.org/10.3319/TAO.2019.03.14.03

Van Camp M, Francis O (2007) Is the instrumental drift of superconducting gravimeters a linear or exponential function of time? J Geod 81(5):337-344. https://doi.org/10.1007/s00190-006-0110-4

Voigt C, Förste C, Wziontek H, Crossley D, Meurers B, Pálinkáš V, Hinderer J, Boy J-P, Barriot J-P, Sun HP (2016) Report on the data base of the international geodynamics and earth tide service (IGETS), GFZ German Research Centre for Geosciences, https://doi. org/10.2312/gfz.b103-16087

Wahr JM (1985) Deformation induced by polar motion. J Geophys Res 90(B11):9363-9368. https://doi.org/10.1029/JB090iB11p09363

Xu C, Yu H, Jian G, Deng S, Zhou B, Wu Y (2019) Low-degree toroidal modes from the Sumatra-Andaman event observed by superconducting gravimeters. Geod Geodyn 10(6):477-484. https://doi.org/ 10.1016/j.geog.2019.07.002

Ziegler Y, Hinderer J, Rogister Y, Rosat S (2016) Estimation of the gravimetric pole tide by stacking long time-series of GGP superconducting gravimeters. Geophys J Int 205(1):77-88. https://doi.org/10. 1093/gji/ggw007 
Open Access This chapter is licensed under the terms of the Creative Commons Attribution 4.0 International License (http://creativecommons. org/licenses/by/4.0/), which permits use, sharing, adaptation, distribution and reproduction in any medium or format, as long as you give appropriate credit to the original author(s) and the source, provide a link to the Creative Commons licence and indicate if changes were made.

The images or other third party material in this chapter are included in the chapter's Creative Commons licence, unless indicated otherwise in a credit line to the material. If material is not included in the chapter's Creative Commons licence and your intended use is not permitted by statutory regulation or exceeds the permitted use, you will need to obtain permission directly from the copyright holder.

(c) (i) 